IRA-International Journal of Education \& Multidisciplinary Studies ISSN 2455-2526; Vol.05, Issue 01 (2016)

Pg. no. 50-57

Institute of Research Advances

http://research-advances.org/index.php/IJEMS

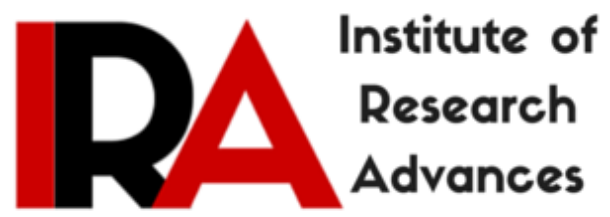

\title{
Improve Debate and Interaction by Providing Technological Platform to XI Class Students at Embassy of India School Moscow (K.V.)
}

\author{
Dharmendra Singh Thakur \\ PGT (Comp.Sci.) \\ Embassy of India School Moscow, Russia.
}

Type of Review: Peer Reviewed.

DOI: http://dx.doi.org/10.21013/jems.v5.n1.p6

\section{How to cite this paper:}

Thakur, D. (2016). Improve Debate and Interaction by Providing Technological Platform to XI Class Students at Embassy of India School Moscow (K.V.). IRA International Journal of Education and Multidisciplinary Studies (ISSN 2455-2526), 5(1), 50-57. doi:http://dx.doi.org/10.21013/jems.v5.n1.p6

(C) Institute of Research Advances

(oc) EY-NC

This work is licensed under a Creative Commons Attribution-Non Commercial 4.0 International License subject to proper citation to the publication source of the work.

Disclaimer: The scholarly papers as reviewed and published by the Institute of Research Advances (IRA) are the views and opinions of their respective authors and are not the views or opinions of the IRA. The IRA disclaims of any harm or loss caused due to the published content to any party. 


\section{Recall:}

I came across the students of Class XI. They were not very confident in operating computers as an aid. Their knowledge and approach was very outdated and I thought of upgrading their skills so as to suit the requirements of modern day practices.

\section{Problem:}

I. Were a little intimidated by coming face to face with others student across the globe.

II. Did not have the requisite contents to interact.

III. Did not possess the required skills.

IV. Were not quick and alert enough.

V. Did not know how to work in a team.

\section{Tentative solution of problem:}

I. Talked to the students about their inhibition to step forward in technological domain.

II. Their hesitation in giving their expertise open heartedly.

III. Ensured their regular presence in the class.

IV. Counseled their team leader to motivate each one in the team.

V. Had a one to one talk with the parents also regarding their participation and contribution to fulfill our goals.

\section{Planned or thought to solve your problem:}

I. Collected the required data like their email-ID's and contact no. of parents.

II. Planned to interact with them via Skype, face time, messenger, Google,$+ \mathrm{KV}+$ and other related technological apps.

III. Write a blog related to the topic and ask for feed back.

IV. Posting motivational and instructional videos on $\mathrm{KV}+$ and you tube and requesting for feed back.

V. Creating a lounge for discussion and debates( Virtual).

\section{Collection of information:}

I. From their school records and class teacher.

II. Academic record from the exam department.

III. Questionnaire related to the topic.

IV. Conduct a survey.

V. Organize a group discussion. 


\section{Time spent on data collection:}

Since July 2015 the realization of a gap was noticed and an informal chat was held with the director of the institute. He also suggested ways and means to overcome the hitch. By then I had realized that without motivation we shall not be able to achieve our targets. Therefore began then itself to gather the resources so that we are comfortable in next six months or so.

\section{Hurdles faced in collecting data:}

I. Non availability of complete records at times

II. People handling the students previously had been posted out.

\section{Conclusion (Analyse \& Interpretation of Data) :}

I. Data was scrutinized very minutely and conclusion was drawn that students are now ready to open up a launch pad to market them self in the world. We realized that by implementing the following features are target can be achieved effectively. They are follows:

a. Windows

b. Chat features

c. Smart Search

d. Stress busters like fun activities, quiz, maze, Sudoku, grid etc.

e. Latest updates and notification available

f. Facilities from other affiliated boards like DPS etc. are online to counsel and guide queries.

g. Feedback on programmes is instant and reflexive.

h. Videos/images relevant to subject matters can be shared too with the fraternity.

i. A wide outreach all over the world with minds striving towards excellence in the field of education \& e-Learning.

j. Accessible, professional in approach and pin pointed focus on the learning outcomes.

k. It is a free to use software that helps to create environment where the students can interact with their teachers and clarify their doubts and also work on their home works and tests.

I. They can also enrich their vocabulary with the help of the offline dictionary.

m. At the same time there are e-Books and games for students provided as entertainment.

\section{Changes after implementing the solution: The outcomes were seen as follows:}

The KV+ Team is a small group of students in the Embassy of India School Moscow who are functioning under the guidance of their Computer Science teacher. These young Technocrats, with the help of their acumen in their favorite field, have opened an interactive platform for all the stakeholders so as to enhance the interface and interaction between students and their subject teachers and also develop a comfortable relationship with their mentors. The online site offers sections like latest updates, blogs, chats, comments, and so much more. The enthusiastic response from the students and teachers' fraternity has been tremendously encouraging. The site organizes the ideas of all the members therein and was formally launched in the month of September 2015 with a terrific response.

The KV+ team caters to the needs of all the sections of KVS family. The basic idea behind it is to focus on the feedback and comments received by the members which shall help them in expanding their horizons, to touch the skies successfully with glory. The site gives wings to new brainstorming and debate. It inspires new ideas. This only can install confidence and entrepreneurial skills among students. 

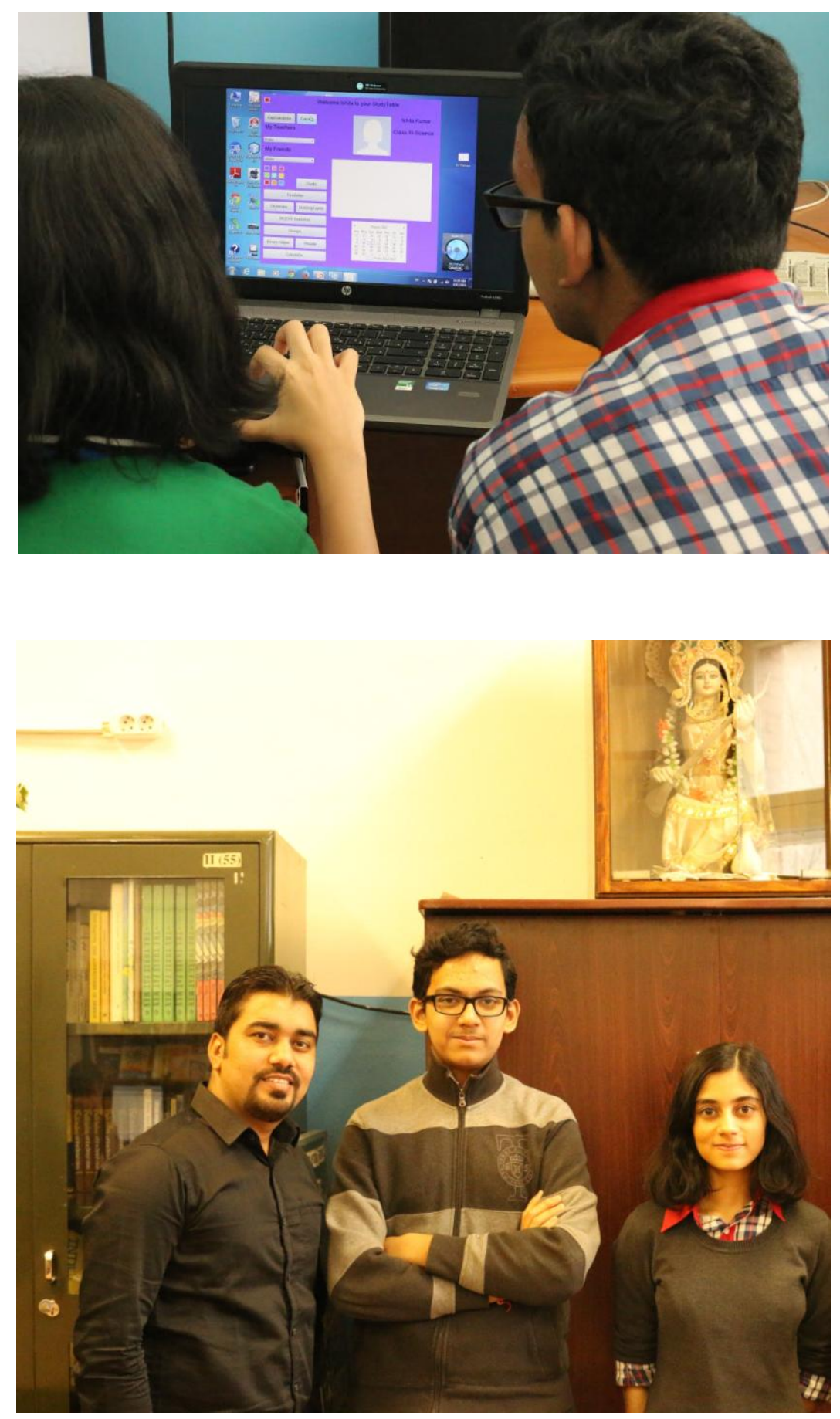

Beyond the technical boundaries! 


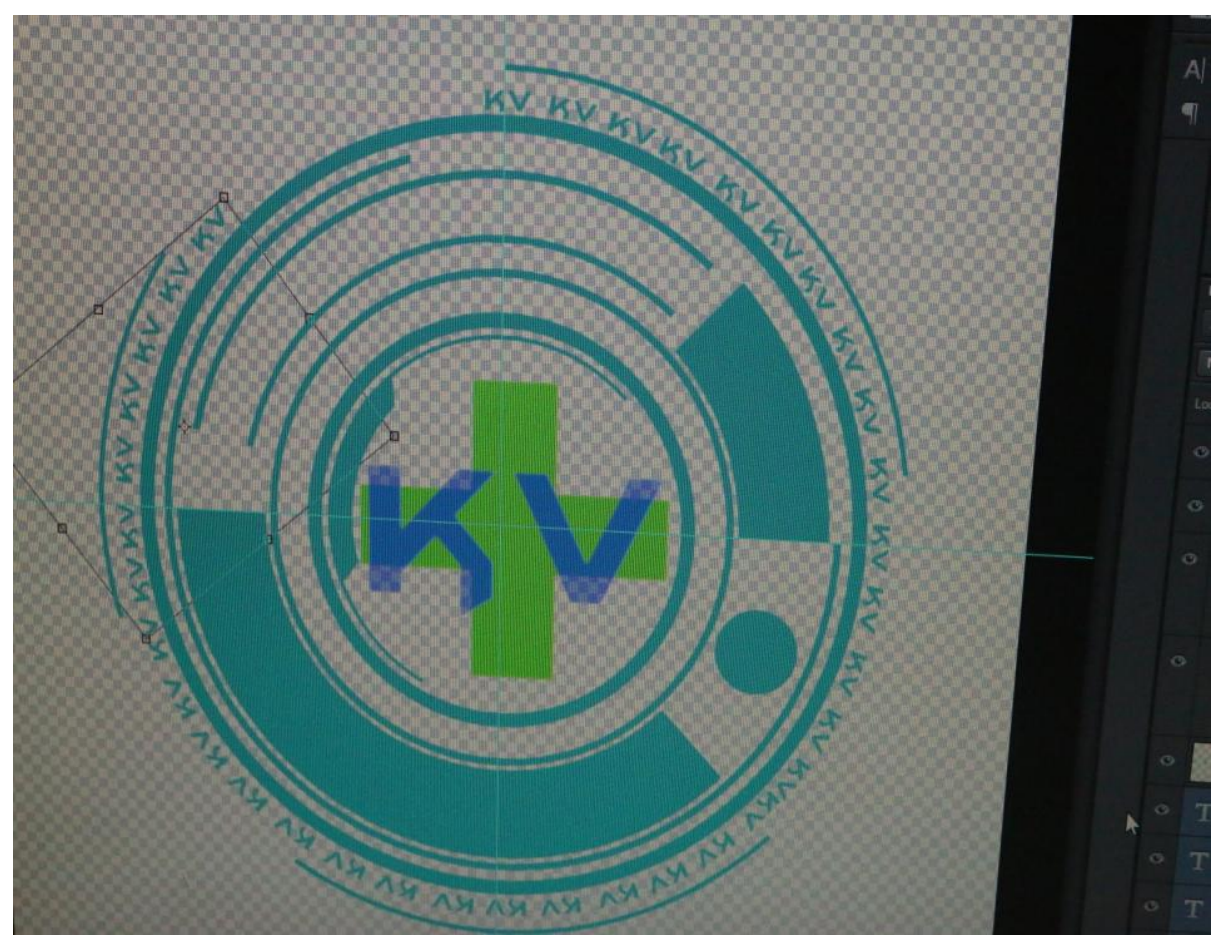

Synergy at work!

\section{Learning outcomes are assessed by-}

- Feedback based on updates/comments from society, teachers, members, parents, peers, etc.

- Projects planned along with their reports.

- Activity sheets/ worksheets

- Evaluations sheets

- Questionnaires

- Survey

- Informal testing

\section{Yes, (Informal type only)}

Certification from parents/ peers colleagues etc. on an informal basis.

Once the programme is implemented on a large scale globally then a formed certification can be planned too.

\section{Find solution of your problem:}

a. Help students have a free online and offline interaction with students from others KV's and teachers from all over the world.

b. Encourage students to be bold and confident in their expression. 
c. Motivate their creative skills.

d. Motivate students and other member to express their theoretical knowledge and share newer ideas.

e. Help students to clarify genuine doubts.

f. Help students to find their way through mature navigation under the supervision of the C.S. team at EOIS Moscow.

g. Encourage learners to evolve and grow in their subject under a friendly watchful eye of the mentors.

h. Motivates students to think beyond- out of the box.

i. Show cases their thoughts and projects and thereby getting a feedback which helps them grow.

j. Learn online etiquettes and mannerisms.

k. As I firmly believe that modern technology owes ecology an apology: as any sufficiently advanced thought is indistinguishable from magic.

\section{Shared your practice with others:}

\section{Specific objectives of the Action research proposal:}

To help students understand the positive aspects of social network.

a. Help students have a free online and offline interaction with students from others KV's and teachers from all over the world.

b. Encourage students to be bold and confident in their expression.

c. Motivate their creative skills.

d. Motivate students and other member to express their theoretical knowledge and share newer ideas.

e. Help students to clarify genuine doubts.

f. Help students to find their way through mature navigation under the supervision of the C.S. team at EOIS Moscow.

g. Encourage learners to evolve and grow in their subject under a friendly watchful eye of the mentors.

h. Motivates students to think beyond- out of the box.

i. Show cases their thoughts and projects and thereby getting a feedback which helps them grow.

j. Learn online etiquettes and mannerisms.

k. As I firmly believe that modern technology owes ecology an apology: as any sufficiently advanced thought is indistinguishable from magic. 


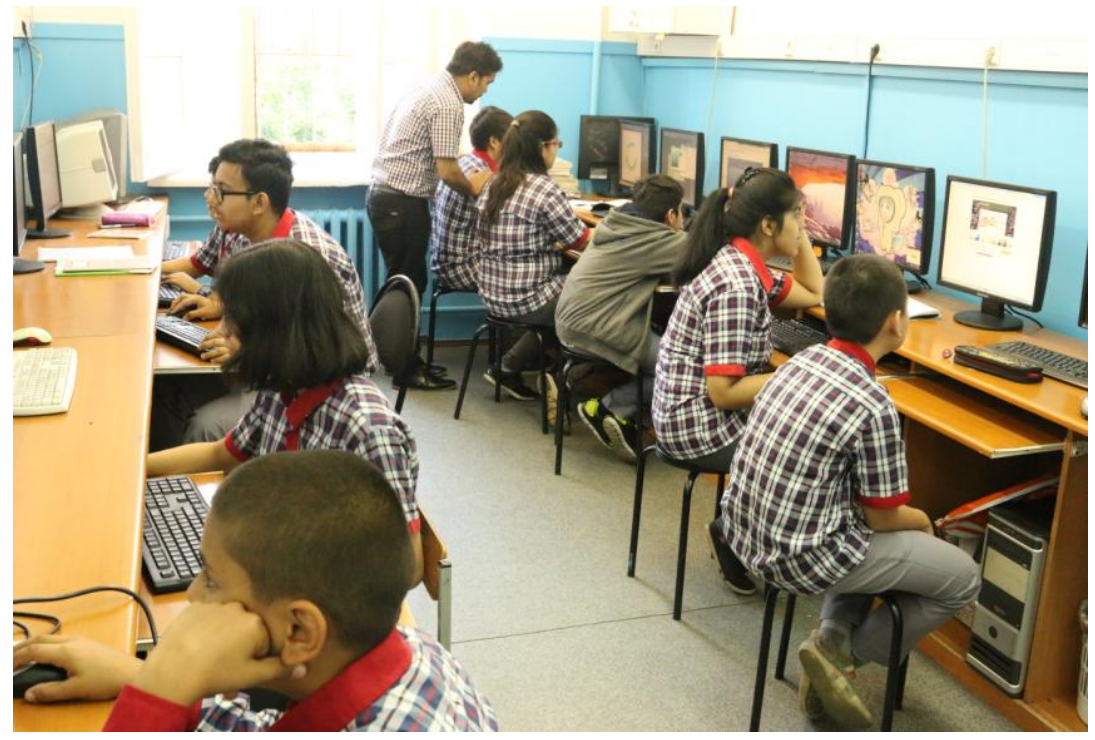

Together we can!

\section{Outreach:}

These students can engage in meaningful dialogues with peers on their favourite topics like sports, latest updates, from the field of technology, tourism and so on. These students have all their energies at a very nascent stage so they get an opportunity to event it positively.

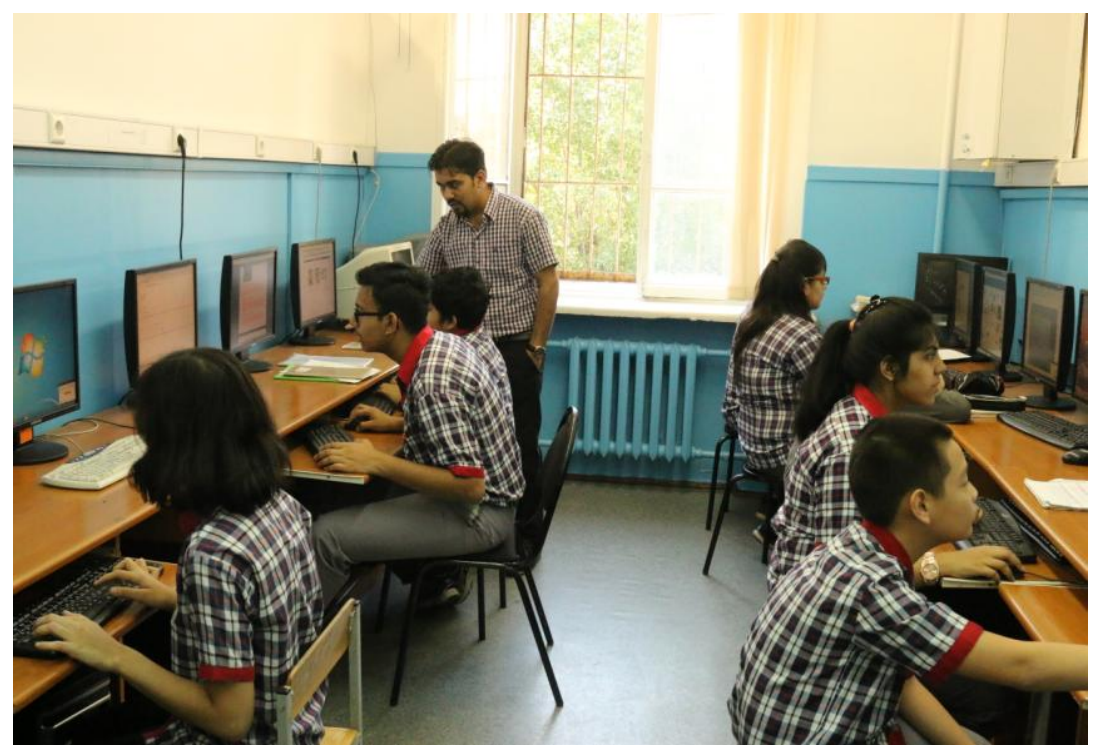

A syncretic mix!

\section{Teaching-learning methodology shared with others:}

How is teaching-learning methodology determined to achieve the goal or address the problem/s? Please describe: It connects teachers and students and helps them interact with one another freely. 
The methodology adopted is of intrinsic kind where the changes take place holistically. The friendly environment thus generated helps foster a bonding between the teacher and the taught. The learner in the process also becomes independent to self-learn.

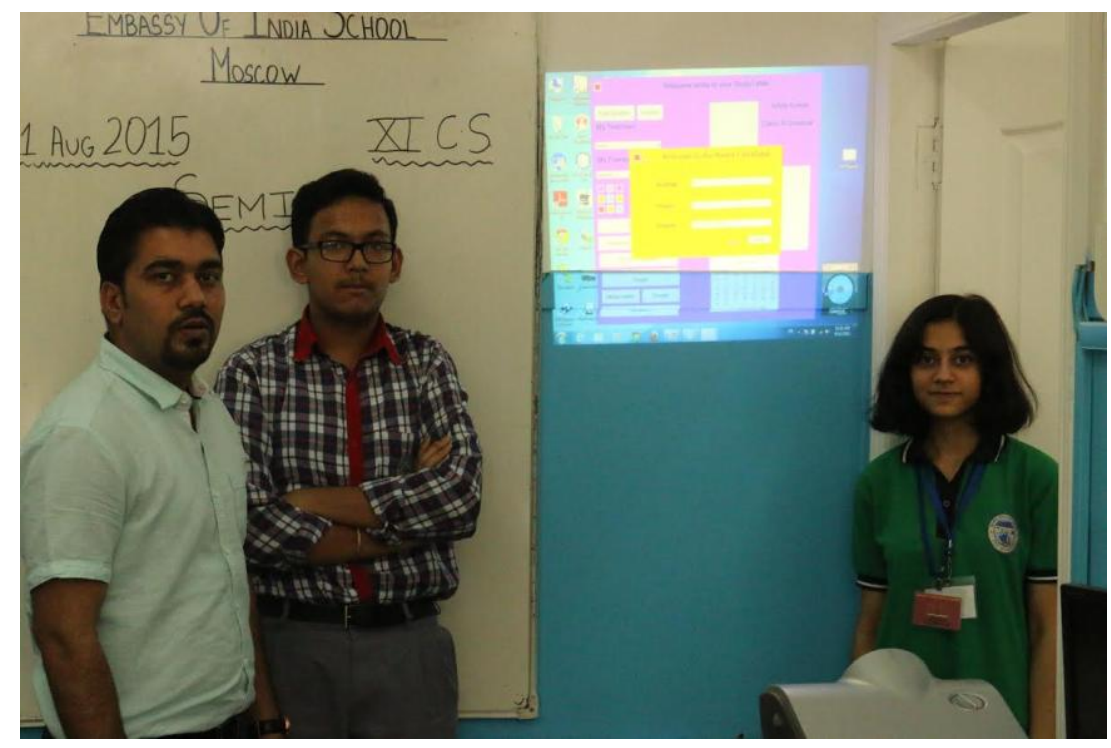

A colourful and meaningful array! 